\title{
Concentrated loads on solid masonry walls - a parametric study and design recommendations
}

\author{
S. Ali and A. W. Page
}

\section{Mr J. Springfield, Carruthers \& Wallace Limited, Toronto}

The potential of papers such as this one is greater than the mere derivation of refined expressions for local bearing stress on masonry under confined bearing plates. Those of us confined daily within the straight-jacket of building codes find it refreshing to discover, or perhaps rediscover, the true nature of the stresses beneath concentrated bearings, revealing the cause of cracks that we have observed in actual walls. Also, this Paper is further evidence in the growing body of knowledge on the mode of failure of brittle materials, strong in compression but weak in tension. The belief in some quarters that concrete never fails in compression, only in tension when it is unconfined, is akin to the mode of failure presented by the Authors. Professor J. Heyman has said that in real stone structures, compressive strength is such that failure is most unlikely if the line of thrust lies within the masonry.

36. To gain a better understanding of the parametric study, I replotted the test results, using actual wall dimensions rather than dimensionless ratios. The curves of load against bearing length tend towards a finite bearing load for zero area because of the increasing intensity of load capacity with decreasing area, in twodimensional space. Replotting Fig. 5 in terms of actual bearing area emphasized the effect of wall length on the capacity of a given bearing area.

37. Provided that the finite element analysis technique employed by the Authors has been verified by several carefully controlled tests, this approach has significant advantages over a parametric testing programme, other than time and cost saving. Consistency of results as the parameters are varied, free of the vagaries of testing, is not the least advantage of this approach.

38. Now that the Authors have competence in the method, I would urge them to apply it to what $I$ feel is a more urgent problem in design: namely that of eccentric loading out of the plane of the wall. This problem requires threedimensional analysis which may be beyond the Authors' current investigation. Indeed, the high bearing capacity with reducing bearing area suggests that failure out of plane has not been considered.

39. There are two aspects to out-of-plane eccentricity: the first form arises from a uniformly loaded bearing plate which is not coincident with the central plane of the wall; the second form arises from the end slope of a beam framing perpendicularly into the wall. It is common practice to proportion the bearing 


\section{DISCUSSION}

plate for the permissible (and conservative) uniform bearing stress. When considering wall stability, as distinct from bearing stress, it is frequent practice to fall back on some pseudo-elastic concept and to consider the bearing pressure distribution to be triangular in order to arrive at an eccentricity. In fact, the beam must tend to bear on the edge of the bearing plate towards the span, creating a high local bearing stress. I have observed local failure of the inner face of concrete block masonry at the inner face, under bearing plates. This leads to the consideration of how far from the face of masonry a bearing plate should be placed. I recall that twenty-five years ago it was the practice in my firm to provide a "bearing bar' under steel beams centred on the bearing plate, if the depth to span ratio of the beam was 18 or more.

40. Since the Paper addresses the effects of bearing on masonry, it is appropriate to question the unrealistic practice used in the design of bearing plates. Some stipulated bearing stress is used to proportion bearing plates on the basis of uniform stress distribution. Having regard for the high rigidity of the masonry relative to the flexural rigidity of the base plate, the concept of uniform bearing stress is unsupportable except on the grounds of simplicity. While the retention of such methods may be justifiable for trivial designs, more realistic techniques should be available for more critical designs.

41. May I suggest that, as an extension of their present investigation, the Authors consider research into such aspects of bearing.

\section{Dr Ali and Dr Page}

It is pleasing to hear that the Paper does help to clarify the mechanism of failure of masonry walls subjected to concentrated loads, a problem commonly encountered in practical design situations. We would support $\mathbf{M r}$ Springfield's comment that cracking in brittle materials such as concrete and masonry subjected to compression is often a transverse tensile failure induced by the applied compression. A useful discussion of this phenomenon with relation to masonry has been published recently by Shrive. ${ }^{23}$

43. We would also agree with the observation that the wall length has a significant influence on the degree of enhancement. For a given loading plate size, the enhancement converges to a constant amount once the wall exceeds a certain length, on account of the decreasing contribution of the masonry further away from the load.

44. The finite element model has been verified by carefully controlled tests. A more detailed description of this verification is contained in reference 24 . As the contributor notes, once a realistic analytical model is available, it becomes an extremely effective tool for parametric studies. The results of those parametric studies have been combined recently with all previously reported concentrated load tests, and detailed design recommendations developed. ${ }^{25}$

45. It is agreed that the case of eccentric load needs to be considered. A realistic three-dimensional study of this problem is much more complex, both in the development of representative constitutive relatives for the material and in the complexity of the computing. An elastic three-dimensional study of this problem has been performed, and this may be of some use. ${ }^{1}$ Work is continuing in this area at the University of Newcastle, particularly with regard to the behaviour of hollow masonry. It is interesting to note that in the study described in reference 25 , test results for wallettes subjected to eccentric path loads still fell within the general scatter of results, and were therefore included within the lower-bound empirical 
relationship suggested for design. For long span beams spanning at right angles to a wall, as Mr Springfield notes, local spalling can occur at the edge of the wall directly beneath the load. This can be avoided by the use of bearing pads or soft material under the first $25-30 \mathrm{~mm}$ of bearing. A study on the influence of bearing plate stiffness is also included in reference 1 .

\section{References}

23. SHRIVE N. G. Compressive strength and strength testing of masonry. Proc. 7 th Int. Conf. on Brick Masonry, Melbourne, 1985, 1, 699-710.

24. Ali S. and PAGe A. W. Finite element model for masonry subjected to concentrated loads. J. Struct. Div. Am. Soc. Civ. Engrs, 1988, 114, No. 8, Aug., 1761-1784.

25. Page A. W. and Hendry A. W. Design rules for concentrated loads on masonry. Struct. Engr, 1988, 66, No. 17, Sept., 273-281. 